\title{
PHYSIOTHERAPISTS' APPROACH REGARDING SPASTICITY MEASUREMENT SCALES IN PATIENTS WITH UPPER MOTOR NEURON SYNDROME
}

\section{Junaid Farooq', Muhammad Asif', Hira Islam Rajput ${ }^{2}$, Muhammad Atif Khan², Muhammad Riaz Baig Chughtai', Noman Ahmed Issani ${ }^{2}$}

\begin{abstract}
OBJECTIVE: To determine the physiotherapists' approach regarding spasticity measurement scales in patients with upper motor neuron syndrome.

METHODS: This cross-sectional study was conducted in different hospitals of Karachi from January 2018 to June 2018. One hundred physiotherapists with an interest in the neurological rehabilitation were enrolled using conveniencesampling technique. After taking written informed consent, a questionnaire comprising of close-ended questions was distributed among the participants. Extraction sheet was used to extract the recorded response; later was analyzed using SPSS $v 21.0$.
\end{abstract}

RESULTS: Out of 100 physiotherapists, 90 responded (response rate of $90 \%$ ), where $60(66.6 \%)$ participants were males and $30(33.3 \%)$ were female. Fifty-five $(61.11 \%)$ participants responded that they use assessment scale of tone for shoulder complex, seven (7.78\%) used biomechanical approaches, five $(5.56 \%)$ used neurophysiological, three (3.33\%) use both biomechanical as well as neurophysiological approach for the assessment of tone in shoulder complex and twenty (22.22\%) did not use any measurement scale. Out of 55 participants using any assessment scale, twenty (36.4\%) used Modified Ashworth Scale (MAS), while rest of thirty-five $(63.6 \%)$ used three grade muscle tone scale with different combination: mild/moderate/severe by twenty ( $36.4 \%)$; flaccid/normal/spastic by five $(9.1 \%)$, and $+/++/+++$ by ten ( $18.1 \%)$ participants.

CONCLUSION: Majority of participants in this study use unreliable assessment tools for the assessment of tone in upper motor neuron syndrome. They need to be encouraged to use valid and reliable tools for assessment.

KEY WORDS: Upper neuron motor syndrome (Non-MeSH), Spasticity scales (Non-MeSH), Physiotherapists' approach (Non-MeSH), Measuring Scales $(\mathrm{MeSH})$.

THIS ARTICLE MAY BE CITED AS: Farooq J, Asif M, Rajput HI, Khan MA, Chughtai MRB, Issani NA. Physiotherapists' approach regarding spasticity measurement scales in patients with upper motor neuron syndrome. Khyber Med Univ J 2020; I 2(2): I I7-20. DOI: I 0.35845/kmuj.2020.18679.

\section{INTRODUCTION}

S pasticity results from a number of upper motor neuron (UMN) lesions and has both diagnostic and therapeutic significance. UMN syndrome is a general term used to describe patients with abnormal motor function secondary to lesions of cortical, subcortical, or spinal cord structures.' In UMN syndrome, the shoulder complex is open to spasticity or flaccidity, subluxation, loss of muscular coordination, soft tissue rupture, altered sensation, frozen shoulder, abnormal patterns of muscle activation and pain. ${ }^{2-4} \mathrm{~A}$ relatively minor problem in the shoulder joint may seriously impair the patients' ability to achieve independence in everyday activities such as feeding, dressing, transfer, and wheel chair ambulation. ${ }^{5-7}$ The spasticity is 'a motor disorder characterized by a velocity dependent increase in tonic
I. College of Physiotherapy, Jinnah Postgraduate Medical Centre, Karachi, Pakistan

2. Isra Institute of Rehabilitation Sciences, Isra University Karachi Campus, Karachi, Pakistang

Email :hirarajputh@hotmail.com Contact \#: +92-334-3217735

$\begin{array}{ll}\text { Date Submitted: } & \text { September 27, 2018 } \\ \text { Date Revised: } & \text { April 03, 2020 } \\ \text { Date Accepted: } & \text { April 07, 2020 }\end{array}$

stretch reflexes (muscle tone) with exaggerated tendon jerks (phasic stretch reflex) resulting from hyper excitability of the stretch reflex..$^{8-9}$ In spasticity, the shoulder joint is adducted tightly against the chest wall and internally rotated; the spastic adductors and internal rotators of the shoulder can severely affect the functional abilities of patients. ${ }^{8}$ In post stroke upper limb spasticity, $75 \%$ of patients experience pain in the shoulder girdle. ${ }^{9-10}$ Measurement of spasticity is important because it determines the effectiveness of any treatment intervention.' Nowadays, the nature of spasticity, its underlying mechanism and its relevance to clinical practice are widely investigated and debated. ${ }^{12}$ The treatment of spasticity is a central part of the clinical management of patients with UMN syndrome and considerable resources are still used to develop and enhance the anti-spasticity treatment protocol. It is very important to establish diagnosis, prognosis and planning of treatment. Without measuring outcomes after any clinical intervention, it would be impossible to decide when to modify the treatment protocol. ${ }^{13,14}$ Although, clinical scales offer a form of quantitative information and have been used in a number of clinical studies, they are still limited by poor reliability and low sensitivity to slight variation in spasticity. ${ }^{14}$

Spasticity in the shoulder joint is a very distressing factor that may cause soft tissue changes, contractures, pain and may cause limited arm functions. The majority of research publications concern the assessment of spasticity in the knee, ankle and elbow joints. ${ }^{15}$ However, spasticity at the shoulder joint has not been considered in the majority 
TABLE I: ASSESSMENT SCALE USED FOR THE MEASUREMENT OF SPASTICITY IN UPPER MOTOR NEURON SYNDROME $(\mathbf{N}=90)$

\begin{tabular}{|l|c|c|}
\hline \multicolumn{1}{|c|}{ Variables } & Frequency & Percentage \\
\hline Scales of tone assessment & 55 & $61 . I$ \\
\hline Neurophysiological assessment tools for tone assessment & 5 & 5.6 \\
\hline Biomechanical assessment tools for tone assessment & 7 & 7.8 \\
\hline Both neurophysiological and biomechanical assessment tool & 3 & 3.3 \\
\hline Did not use any scales for assessment & 20 & 22.2 \\
\hline
\end{tabular}

TABLE II: TYPES OF SCALES USED FOR THE ASSESSMENT OF TONE $(\mathbf{N}=55)$

\begin{tabular}{|l|c|c|}
\hline \multicolumn{1}{|c|}{ Variables } & Frequency & Percentage \\
\hline Three grade muscle tone scale (Mild / Moderate / Severe) & 20 & 36.4 \\
\hline Three grade muscle tone scale (Flaccid / Normal / Spastic) & 5 & 9.1 \\
\hline Three grade muscle tone scale (+ / + / +++) & 10 & 18.1 \\
\hline Modified Ashworth Scale (MAS) & 20 & 36.4 \\
\hline
\end{tabular}

of research papers. Spasticity is found to be a major contributor of contracture in the stroke population. ${ }^{16}$ Another study pointed out that in his survey the majority of healthcare professionals agreed that the measurement of spasticity is important. ${ }^{17}$ This study was conducted to determine the physiotherapists' approach for the assessment of spasticity at the shoulder joint and outline specific techniques used by physiotherapists dealing patients with upper motor neuron syndrome.

\section{METHODS}

This cross-sectional study was initiated after taking approval from Institutional Ethical Review Committee (IERC) of Isra Institute of Rehabilitation Sciences, Isra University, Karachi Campus and a sample of 100 physical therapists were enrolled conveniently. The study was conducted from January 2018 till June 2018. After taking informed written consent, data was collected from different hospitals and physical therapy clinics of Karachi i.e., Al-Tibri Medical College \& Hospital, Al-Mustafa Hospital, Mamji Hospital, Trauma Centre, Rabia Moon Institute of Neurosciences \& Rehabilitation, The Doctor's Plaza Clinic, Al-Sehat Rehabilitation Clinic and Dr. Ikram Baig Chughtai Physiotherapy Clinic. The sample size of this study was 100 based on all available physiotherapists conveniently. The participants aged between $25-50$ years and having experience of at least 02 years in dealing neurological patients were included in the study; however, the physical therapists denying taking part in study or filled an incomplete from were excluded. A pre-validated questionnaire was self-administered. The performa was designed to explore participants' demographic details: age, qualifications, place of work clinical experience, and included questionnaire which had closed ended questions related to participants' clinical work including assessment tools of spasticity in the upper motor neuron syndrome. Mean, frequency and percentage were calculated for all the variables. Statistical analysis was performed by using SPSS software package version 21 .

\section{RESULTS}

Out of 100 physiotherapists, 90 responded with a response rate of $90 \%$. Out of 90 participants, finally included in study, $60(66.6 \%)$ were males and 30 (33.3\%) were females. Mean age of participants was $37.13 \pm 4.849$ years. Fifty $(55.6 \%)$ participants had working experience of $\mathrm{II}$ to 20 years with neurological patients, while 40 (44.4\%) had experience between 2 to 10 years.

Table I represents used of assessment scale for the measurement of spasticity in upper motor neuron syndrome, in which $55(61.1 \%)$ used scale for assessment.

The types of scale used for the assessment of tone are given in Table II, which shows that three-grade muscle tone scale (mild/moderate/severe) and Modified Ashworth Scale (MAS) was used by $20(36.4 \%)$ participants each .

\section{DISCUSSION}

According to the findings of our study, majority of the physiotherapist had more than 10 years' experience of managing neurological patients and three-grade muscle tone scale (mild/moderate/severe) and Modified Ashworth Scale (MAS) the most commonly used scales for the measurement of spasticity. These results are similar to previous studies ${ }^{11,17}$ but "three-grade" scales have shown poor reliability as the majority of physiotherapists are using these scales, it is easy to transfer the information between the therapist and clinics. ${ }^{18}$ It is still not clear that how physiotherapists apply this scale to their patients. Participants in this survey reported that they used observation and palpation methods to measure spasticity. Although handling patient forms a basic part of assessment, it cannot be considered as measurement tool.

A major problem with this assessment method is that it does not appear as a recorded scale for the therapists and no documented evidence could be found that tested its reliability and validity. Only few participants used Modified Ashworth Scale although it has been used in the majority of clinical trials as a measure of spasticity. De Azevedo, et al. $^{19}$ reported the reliability of the Modified Ashworth Scale for the elbow joint although believed that more appropriate statistical analysis is required to determine the reliability of the scale. ${ }^{2}$ Another study raised questions about the validity and reliability of Modified Ashworth Scale. ${ }^{21-}$ ${ }^{22}$ Synnot, et al. ${ }^{14}$ also raised the question about the practical use of the Modified Ashworth Scale and stated that it is difficult to grade a joint that has a minimal amount of tone that is present in more than half the available range. It is interesting that no participants used the Modified Tardieu Scale for the assessment of tone in the shoulder complex. Although, recent studies suggested that Modified Tardieu Scale is more reliable than Modified Ashworth 
Scale and can differentiate between neural and non-neural components causing resistance to passive movement. ${ }^{18,23}$

It is evident that there is a difference in the research work carried out by the rehabilitation scientists and physiotherapists working in the clinics. ${ }^{24}$ Rehabilitation scientists are working to develop tools that provide quantitative information about the spasticity and differentiate between neural and nonneural complications associated with spasticity. ${ }^{25}$ The results of this study are very much similar to the previous studies already discussed earlier. It is evident that in clinical practice the majority of physiotherapists are using unreliable outcome tools for the assessment of tone. In research the rehabilitation scientists now are working to develop more objective outcome tools. On the other hand scientists are also exploring the relationship between spasticity and its effect on the functional independence of patients. ${ }^{26}$

This study did not consider the wide differences in experiences of physiotherapists, neither socioeconomic levels of their patients, nor the quality/quantity of treatment those patients would get based on their assessment. These variables may be considered in future researches. Physiotherapist should be encouraged to introduce reliable and valid tools for the assessment of spasticity. Rehabilitation scientists are working to develop tools for objective assessment of spasticity but the practical applications of such tools in the clinical settings must be assessed. The measurement tools need to be simple, user friendly and quick in use to encourage clinician to practice them. It is also important to test the reliability and validity of the equipment on all the major joints of the body.

\section{CONCLUSION}

A high frequency was recorded for The study concludes that majority of physiotherapists are using unreliable assessment tools for the assessment of tone in upper motor neuron syndrome. Biomechanical approaches, neurophysiological approaches and complex instruments are generally not used by the therapists in the clinics. Physiotherapists largely use relatively simple and easy outcome tools for assessment. They need to be encouraged to use valid and reliable tools for assessment.

\section{ACKNOWLEDGEMENTS}

We pay our deepest gratitude to Dr. Muhammad Athar Majeed Khan for their guidance. We would like to thanks all those who contributed at any stage in the completion of this study.

\section{REFERENCES}

I. Dewey CW, Costa RC. Functional and dysfunctional neuroanatomy: the key to lesion localization.In: A practical guide to canine and feline neurology. 3 rd ed. New Zeeland;Wiley-Blackwell:20I 5. [Accessed on: August 18, 2018]. Available from URL: https:// www.wiley.com/en-us/Practical + Guide + to + Canine + and +Feline + Neurology\%2C+3rd+Editionp-978III 9062042.

2. Eriks-Hoogland I, De Groot S, Snoek G, Stucki G, Post M, Van Der Woude L. Association of shoulder problems in persons with spinal cord injury at discharge from inpatient rehabilitation with activities and participation 5 years later. Arch Phys Med Rehabil 2016;97(I):84-9I. DOI: 10.1016/ j.apmr.20I5.08.432.

3. Rapidi C, Kyriakides A. People with spinal cord injury in Greece. Am J Phys Med Rehabil 20 I 7;96(2):7I-3.

4. Turner-Stokes L, Jackson D. Shoulder pain after stroke: a review of the evidence base to inform the development of an integrated care pathway. Clin Rehabil 2002; 16(3):276-98. DOI: 10.1191/ 0269215502cr49loa.

5. Donatelli R. Physical Therapy of the Shoulder. 5 th ed; Churchill Livingstone: 2012. [Accessed on: August 18, 2018]. Available from URL: https://www.elsevier.com /books/physical-therapy-of-theshoulder/donatelli/978-I-4377-
0740-3.

6. Fotiadis F. Grouios G. Ypsilanti A. Hatzinkolaou K. Hemiplegic shoulder syndrome: possible underlying neurophysiological mechanisms. Phys Ther Rev 2005; I0(I):5I-8. DOI: 10.1179/ $108331905 \times 43445$.

7. Watkins CL, Leathley MJ, Gregson JM, Moore AP, Smith TL, Sharma AK. Prevalence of spasticity post s t roke. Clin Rehabil 2002; 16(5):515-22. DOI: 10.1191/ $0269215502 \mathrm{cr} 5120$.

8. Weidner N, Rupp R, Tansey K. Neurological aspects of spinal cord injury. Ist ed. Switzerland; Springer International Publishing:2017. [Accessed on: August 18, 2018]. Available from URL: https://www. springer.com/gp/book/9783319462 912.

9. Pizzi A, Carlucci G, Falsini C, Verdesca S, Grippo A. Evaluation of upper-limb spasticity after stroke: A clinical and neurophysiologic study. Arch Phys Med Rehabil 2005;86(3):410-15. DOI: 10.1016/ j.apmr.2004. 10.022.

I0. Bavikatte G, Gaber T. Approach to spasticity in General practice. Brit J Med Pract 2009;2(3):29-34.

II. Blanchette AK, Demers M, Woo K, Shah A, Solomon JM, Mullick AA, et al. Current practices of physical and occupational therapists regarding spasticity assessment and treatment. Physiother Can 2017;69(4):303-12. DOI: 10.3138/ ptc. 2016-54

12. Li S. Spasticity, motor recovery, and neural plasticity after stroke. Front Neurol 2017;8: I20. DOI: 10.3389/ fneur.2017.00I20.

13. Fridén J, Lieber RL. Spastic muscle cells are shorter and stiffer than normal cells. Muscle Nerve 2003; 27(2): I57-64. DOI: 10.1002/ mus . 10247

14. Synnot A, Chau M, Pitt V, O'connor D, Gruen RL, Wasiak J, et al. Interventions for managing skeletal muscle spasticity following traumatic brain injury. Cochrane Database Syst Rev 2017; II: 
CD008929. DOI: 10.1002/ | 465 | 858.CD008929.pub2

15. Bhakta BB. Management of spasticity in stroke. Br Med Bull 2000;56(2): 476-85. DOI: 10.1258 /0007/4200 |903||I.

16. Burridge $\mathrm{JH}$, Wood DE, Hermens $\mathrm{H}$, Voerman GE, Johnson GR, Wijck FV, et al. Theoretical and methodological considerations in the measurement of spasticity. Disabil Rehabil 2005; 27(I-2):69-80. DOI: 10.1080/ 09638280400014592.

17. Kahn MB, Mentiplay BF, Clark RA, Bower KJ, Williams G. Methods of assessing associated reactions of the upper limb in stroke and traumatic brain injury: a systematic review. Brain Inj 20I6;30(3):252-66. DOI: 10.3109/02699052.2015.1|17657

18. Lo WLA, Zhao JL, Chen L, Lei D, Huang DF, Tong KF. Between-days intra-rater reliability with a hand held myotonometer to quantify muscle tone in the acute stroke population. Sci Rep 2017;7(I): I4I 73 .
19. De Azevedo ER, Maria RM, Alonso KC, Cliquet JR A. Posture influence on the pendulum test of spasticity in patients with spinal cord injury. Artif Organs 20I5;39(I2):I033-7. DOI: |0. I I / aor. 2500.

20. Sunnerhagen KS, Francisco GE. Enhancing patient-provider communication for long-term poststroke spasticity management. Acta Neurol Scand 2013;128(5):305-10. DOI: I0.1 III/ane. I2I 28

21. Adams MM, Hicks AL. Spasticity after spinal cord injury. Spinal Cord 2005;43(I0):577-86. DOI: 10.1038 /sj.sc.3101757.

22. Sæther R, Jørgensen L. Intra-and inter-observer reliability of the Trunk Impairment Scale for children with cerebral palsy. Res Dev Disabil 20II;32(2):727-39. DOI: 10.1016 /j.ridd.2010.1 I.007.

23. Lannin NA, Cusick A, Hills C, Kinnear B, Vogel K, Matthews K, Bowring G. Upper limb motor training using a Saebo ${ }^{\mathrm{TM}}$ orthosis is feasible for increasing task-specific practice in hospital after stroke. Aust Occup Ther J 2016;63(6):364-72. DOI :10.1III/I440-1630.12330

24. Yam WK, Leung MS. Interrater reliability of Modified Ashworth Scale and Modified Tardieu Scale in children with spastic cerebral palsy. J Child Neurol 2006;2I(I2): I03I-5. DOI: I0.II I7/70I0.2006.00222

25. Burchiel KJ, Hsu FP. Pain and spasticity after spinal cord injury: mechanisms and treatment. Spine (Phila Pa 1976) 200I;26(24S):SI4660. DOI: |0.1097/00007632-200| |2|5|-00024

26. Lohmann J, Houlfort N, De Allegri M. Crowding out or no crowding out? A Self-Determination Theory approach to health worker motivation in performance-based financing. Soc Sci Med 2016;169:I8.DOI: 10.1016/j.socscimed . 2016 .09 .006 .

\section{AUTHORS' CONTRIBUTIONS}

Following authors have made substantial contributions to the manuscript as under:

JF \& MA: Conception and study design, acquisition, drafting the manuscript, final approval of manuscript to be published.

HIR: Acquisition, analysis and interpretation of data, drafting the manuscript, critical review final approval of manuscript to be published

MAK: Study design, acquisition of data, critical review, final approval of manuscript to be published.

MRBC: Conception and study design, critical review, final approval of manuscript to be published.

NAl: Acquisition of data, drafting the manuscript, final approval of manuscript to be published

Authors agree to be accountable for all aspects of the work in ensuring that questions related to the accuracy or integrity of any part of the work are appropriately investigated and resolved.

CONFLICT OF INTEREST
Authors declared no conflict of interest
GRANT SUPPORT AND FINANCIAL DISCLOSURE
NIL

This is an Open Access article distributed under the terms of the Creative Commons Attribution-Non Commercial 2.0 Generic License.

KMUJ web address: www.kmuj.kmu.edu.pk

Email address: kmuj@kmu.edu.pk 